\title{
Exploring Digital Divide in the Maldives
}

\author{
Mohamed Shareef, Adegboyega Ojo, and Tomasz Janowski \\ Center for Electronic Governance, United Nations University IIST, P.O. Box 3058, Macao \\ mohamed@iist.unu.edu, ao@iist.unu.edu, tj@iist.unu.edu
}

\begin{abstract}
The central role of ICT in development and its ethical implications have kept the longstanding discussions of the Digital Divide active in the international development and research communities, with new perspectives on how to measure and interpret this inequality. In this paper, we examine the nature of the Digital Divide in the Maldives - between the nation's capital and the Atolls, between the Atolls and across the nation, and the evolution of these divides over time. In order to inform more effective policy interventions, we also attempt at identifying clusters within the country that share similar Digital Divide concerns. The results show significant disparities in the penetration of digital technologies. While we can observe the narrowing of the Digital Divide over time, the divide remains significant between the capital and the rest of the nation. Finally, we discuss the implications of these results to ICT development of Small Island Developing States.
\end{abstract}

Keywords: Electronic Government, Digital Divide, Maldives, Small Island Developing States.

\section{Introduction}

The advent of the Information Age and rapid developments in Information and Communications Technologies (ICT), particularly the Internet, have created new opportunities for the development of societies and nations. However, the dawn of the Information Society, with its ever-increasing interweaving of ICT into daily lives, has also raised the possibility of exaggerating existing social divides, with ethical implications on key human rights (Universal Declaration of Human Rights - UDHR).

The capacity of the Internet to both empower and discriminate was widely recognised in the mid-1990s [9], giving rise and prominence to the issue of Digital Divide [11]. In particular, with the emergence of Electronic Government, with nations and economies around the world embracing ICT as a strategic tool in public sector modernisation, access to information and service delivery, the phenomenon of Digital Divide brings into focus Article 21 of the UDHR which guarantees individuals the right to take part in the governance of their countries and the right of equal access to public services, among others. With the increasing maturity of Electronic Government, the possible consequences of the Digital Divide in exacerbating existing social, political and economic divides between citizens [24, 25] have serious ethical implications for the delivery of basic human rights [22] across the globe and are a constant 
concern to the international development community, government leaders and ICT policy-makers.

In a recent report on Citizens' Digital Participation [20], the regulator and competition authority for the United Kingdom communications industries, Ofcom, emphasised that while "digital communications have provided new channels for people to interact with democratic institutions and to become engaged in a range of activities associated with citizen participation, they also pose a challenge: a significant section of the population, lacking access to these technologies or the confidence to use them, may become increasingly disengaged". This highlights the relevance and significance of the Digital Divide even in a highly developed country like the United Kingdom.

This paper presents an exploratory study of Digital Divide within the Maldives. It explores the Digital Divide landscape, identifies clusters of ICT penetration in the Maldives, and examines two key development challenges: the country's numerous small island communities and the geographical distribution of these communities across a comparatively vast sea area. The results show large disparities in the penetration of digital technologies, the narrowing of the Digital Divide over time, and a remaining significant divide between the capital and the rest of the nation.

The rest of the paper is structured as follows. Sections 2 and 3 introduce the small island context of the Maldives and the notion of Digital Divide. Section 4 examines the Digital Divide in the Maldives - research questions (Section 4.1), analysis (Section 4.2) and findings (Section 4.3). Section 5 presents some conclusions.

\section{Maldives}

The Republic of Maldives is a Small Island Developing State composed of 26 natural coral Atolls composed of 1,192 small low-lying islands, less than 200 of which are permanently inhabited. These 29 Atolls are divided for administrative and governance purposes into 20 administrative regions, also called Atolls. The furthest Atoll capital is located over 500 kilometres from Male' - the nation's capital.

A large proportion of these inhabited islands have an area of less than half a square kilometre and only a few are bigger than two square kilometres. These islands are spread over 115,300 square kilometres of the Indian Ocean, some 823 kilometres from the northernmost point to the south and some 130 kilometres east to west. Of the 115,300 square kilometres, only 298 square kilometres $(0.26 \%)$ is dry land.

The population of the country is distributed unevenly across 194 islands. According to the 2006 Housing and Population Census, of the 194 permanently inhabited islands, only 4 islands have a population of over 5,000, 131 have a population below 1,000 , and 72 have a population below 500. Over one-third of the population of Maldives lives on the capital island of 1.93 square kilometres - one of the most densely populated cities in the world. See Figure 1.

The smallness of the islands, the distances between them and the large number of island communities are the key obstacles for the development of the country. Leading to severe diseconomies of scale, they greatly challenge the delivery of basic services. Concerning the penetration of ICT, Figure 2 shows the fast rise in mobile telephony and stagnant penetration by fixed phone lines. Figure 2 also shows that the use of the Internet, while increasing, is still relatively limited. 


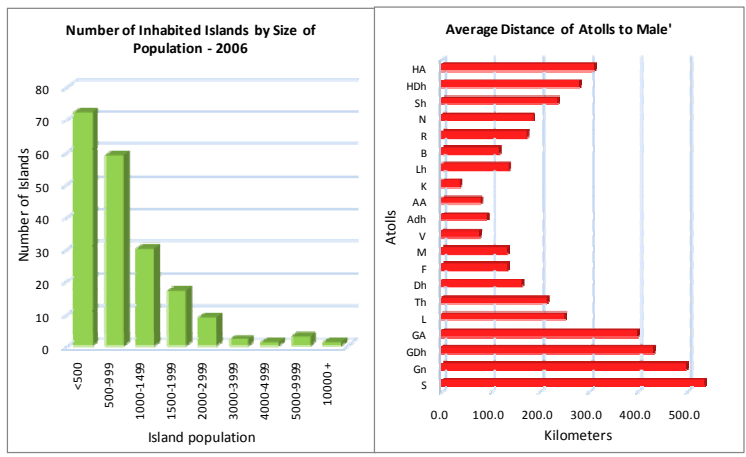

Fig. 1. Geographical and Demographic Distribution of the Maldives [8]

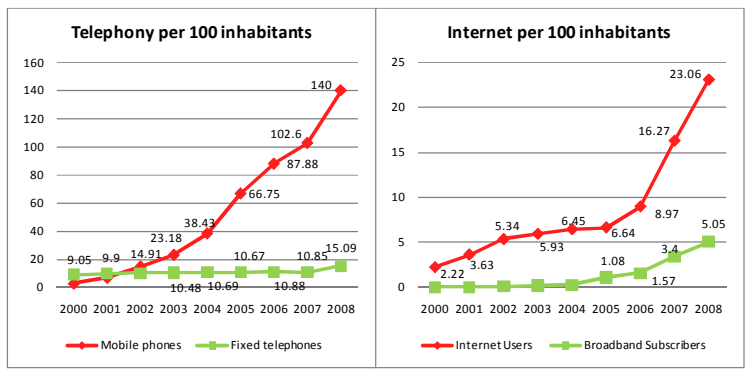

Fig. 2. Growth of Fixed and Mobile Phone Lines [14]

\section{Digital Divide}

\subsection{Defining Digital Divide}

A variety of ways have been used to define and characterise the divisions or disparities among people, societies and nations in terms of their associations with ICT, the so-called Digital Divide. In its simplest form, the Digital Divide refers to the gap existing between those with access to ICT and those without, "a new label for a similar concept of the previous generation: information haves and have-nots" [4]. This dichotomous portrayal of information haves and have-nots often refers to the access to and use of ICT [1], for example in terms of the number of phone lines per inhabitant, or the number of Internet users or mobile telephones in the population.

On the other hand, a broader characterisation of Digital Divide is achieved through a multi-dimensional or multi-perspective approach - identifying and using different types of access and measuring different types of divides. Different types of access include [26]: (1) mental access e.g. digital experience, lack of interest or computer anxiety; (2) material access e.g. possession of computers; (3) skills access e.g. user friendliness, education or literacy; and (4) usage access - usage opportunities. 
Alternatively, Digital Divide can be characterised in relation to or as a mirror of different types of social disparity. According to [19], Digital Divide encompasses: (1) global divide - divergence of Internet access between industrialised and developing countries; (2) social divide - the gap between information rich and information poor within each country; and (3) democratic divide - differences between those who do and those who do not engage, mobilise and participate in public life through ICT.

Across various definitions and portrayals, Digital Divide has been examined and studied using a variety of factors: technological infrastructure $[6,10]$, socio-economic development $[9,10,21]$, socio-political development $[9,21]$, legal and regulatory frameworks $[3,9,10]$, demography $[3,5]$, income [3] and culture [18]. The influence of these factors on Digital Divide depends on their evolution over time [9] and the stage of ICT adoption in a country [5].

For the current paper, we adopt the definition of the Digital Divide from [12] - the gap between those who benefit from digital technologies and those who do not.

\subsection{Measuring Digital Divide}

Given the multifaceted nature of Digital Divide and the fact that it is closely related to and interwoven with various social and human conditions, measuring and quantifying the divide can be also multifaceted.

In its simplest form, Digital Divide can be illustrated by measuring the distribution of ICT across different groups [15], defined based on the factors like age or income. This is a simple way of illustrating the unequal distribution of ICT, and providing a visual representation of the existence of Digital Divide. Another approach is to calculate the ratio of the penetration rates of ICT between groups [13] to identify the gap between groups under analysis, and to track how this gap evolves over time. The gap between groups, expressed as the ratio of ICT penetrations, is a simple quantitative figure representing Digital Divide, showing convergence or divergence of the divide between groups over time. While these approaches capture Digital Divide across groups, they cannot account for many underlying dimensions within the concept [23].

A more rigorous approach to quantifying the disparity or distribution of inequality is to use the Lorenz curve and the Gini coefficient. The Lorenz curve is used to illustrate the distribution or cumulative share of count data across the population, whilst the Gini coefficient summarises the Lorenz curve to a single number representing the degree of inequality within the population. The coefficient varies between 0 and 1 , where 0 represents perfect equality and 1 perfect inequality. The Lorenz curve and Gini coefficient provide a good measure of Digital Divide, applied by both research $[2,16]$ and international development communities [13, 15]. A well-established measure of disparity among groups, it is useful for quantifying Digital Divide across large numbers of entities, and for showing the evolution of the divide over time in terms of changing disparities between groups.

In this paper, we construct the Lorenz curve as a line between consecutive points $(\mathrm{Xk}, \mathrm{Yk}$ ) for the intervals $\mathrm{k}$ ( $\mathrm{k}$ is between 1 and $\mathrm{n}$ ), and estimate the Gini coefficient by approximating the area under the curve with trapezoids, using the formula:

$$
G=\left|1-\sum_{k=1}^{n}\left(X_{k}-X_{k-1}\right)\left(Y_{k}+Y_{k-1}\right)\right|
$$


All methods described above for measuring Digital Divide require defining groups of communities within and between which the measurement of disparity or inequality is carried out. These are often based on the groupings recommended by international organisations like the United Nations or the World Bank, or they are based on existing national or local boundaries, or on factors like demography or race.

This paper applies a different approach. The grouping of people or communities is based on their ICT profiles, using the techniques like the Lorenz curve, Gini coefficient or gap analysis to measure the disparities within and between groups, and ultimately to determine the key determinants of the Digital Divide. This approach not only illustrates and quantifies Digital Divide, but provides a level of support for strategic planning aimed at addressing the divide, based on the clusters of communities which share similar ICT characteristics.

While there are several clustering techniques, we use the Neural Network-Based Clustering method due to its visualisation property. In particular, we use Kohonen's Self Organizing Maps (SOM) [17], a type of artificial neural network that can produce two-dimensional representations of multi-dimensional input spaces, often called maps. Being able to represent groups of communities defined by multiple Digital Divide indicators on a two-dimensional grid helps to identify clusters of entities with similar ICT profiles, and possibly to utilise these clusters to form social infrastructures (e.g. communities of interest) for addressing the Digital Divide.

\section{Digital Divide in the Maldives}

The Maldives is a country of hundreds of small island communities dispersed over a large space of the Indian Ocean. Its unique geography and demography has had a major effect on the development of individual island communities with respect to each other and especially with respect to the nation's capital Male'.

In this section, we identify these divides with respect to the pervasiveness of personal computers and the use of the Internet and fixed and mobile phones, using the household statistics from the 2000 and 2006 Censuses. The section is structured into research questions (Section 4.1), analysis (Section 4.2) and findings (Section 4.3).

\subsection{Research Questions}

The primary goal of this work is to understand the nature of the Digital Divide in the Maldives in order to better inform ICT policy formulation and strategic Electronic Governance planning at the national level. Given the Maldives' peculiar geographic and population features, and their influence on the national-level and Atoll-level development, we focus on how such features impact Digital Divide in the country.

Our investigation proceeds in three steps: (1) establish and quantify Digital Divide in the Maldives, (2) measure the significance of the geographic and demographic features of the Maldives to Digital Divide, and (3) examine the dynamics of Digital Divide in the Maldives. These objectives are framed as two research questions below:

\section{How are the Atolls divided with respect to ICT access?}

In order to understand the pervasiveness of ICT in the Maldives, establishing the existence and magnitude of Digital Divide is important. Earlier studies of various 
disparities in the Maldives tend to compare the haves and have-nots between the capital and the rest of the country, or between individual atolls.

\section{How significant is the geographic and demographic distribution of the Atolls to the Digital Divide?}

Establishing the significance of the distance between the Atolls and Male' and between the islands of an Atoll and its capital, to the disparities in access to ICT may inform national-level development strategies particularly to ensure the narrowing of Digital Divide and increasing benefits from information access. At the same time, as large numbers of small island communities give rise to diseconomies of scale, determining the significance of this feature on ICT diffusion can support better planning for community development and population consolidation. In particular, we investigate Digital Divide with respect to: (1) the average distance of the Atolls to Male' and (2) the number of islands with less than 500 people in an Atoll. These variables capture two key geographic and demographic dispersion characteristics of the nation.

In this work we use access to ICT as primary indicator of Digital Divide, with data on ICT penetration from the 2000 and 2006 Household and Population Census of the Maldives $[6,7]$ which form the primary data used in this analysis.

\subsection{Analysis}

Led by these two research questions, this section documents the analysis of Digital Divide in the Maldives. Section 4.2.1 examines the divide between the capital and the Atolls, Section 4.2.2 examines the divide across the Maldives, and Section 4.2.3 examines the divide between Atolls. Finally, Section 4.2.4 examines the significance of the country's geographic and demographic features on the divide.

\subsubsection{Digital Divide between Male' and the Atolls}

Digital Divide has many facets and can be assessed in many ways. This section illustrates the Digital Divide between the nation's capital and the Atolls, using the distribution of ICT between these two groups. It also examines the evolution of the divide by using penetration ratios.

The distribution of ICT based on the number of households in Male' and the number of households in the rest of the country is shown in Figure 3. As is evident from this illustration, mobile phones and televisions (TVs) are the most evenly distributed: $31 \%$ of the households in the country (in Male') have $33 \%$ of the mobile phones and $31 \%$ of TVs, and $69 \%$ of the households (in the Atolls) have $67 \%$ of the mobile phones and $69 \%$ of the TVs. In contrast, the distribution of fixed lines, personal computers and particularly residential Internet connections clearly distinguishes the capital Male' from the rest of the country (i.e. Atolls): $31 \%$ of the households (in Male') have 59\% of the fixed line phones, $61 \%$ of the computers and $78 \%$ of residential Internet connections. Clearly, Digital Divide is severe with respect to Internet access, with $31 \%$ of the households (in Male') having 78\% of the household Internet connections.

Given a clear divide between Male' and the Atolls, we now investigate the evolution of this divide using census data from 2000 and 2006. While the divide is most prominent with respect to Internet pervasiveness, the data on household Internet was 


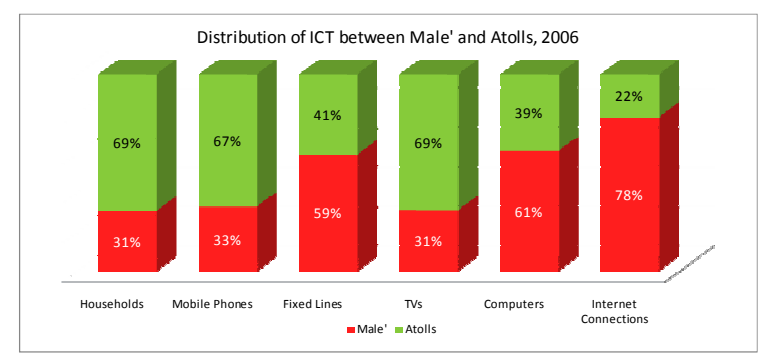

Fig. 3. Distribution of ICT based on the numbers of households in Male' and the Atolls, 2006

not collected during the 2000 Census, so we can only analyse penetration of computers and fixed phone lines. To this end, we use the ratio of penetration as a measure of the divide (or gap) between Male' and the Atolls.

Figure 4 shows the progression of the divide between Male' and the Atolls with respect to the percentages of households with computers (left) and fixed phone lines (right) for 2000 and 2006. The divide, measured as the ratio of the penetration rates, shows that while the absolute difference between percentages of the households with personal computers has increased from 2000 to 2006, the divide between Male' and the rest of the Atolls has actually decreased from 16.8 to 3.6. With respect to fixed phone lines, not only has the gap decreased but the absolute difference did so as well, clearly indicating the narrowing of the divide between Male' and the Atolls between 2000 to 2006.

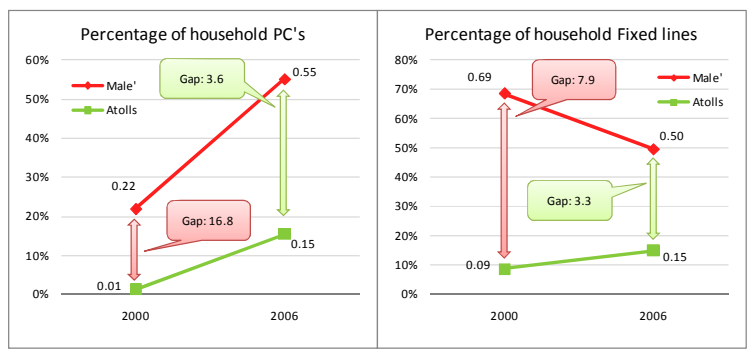

Fig. 4. Evolution of the Digital Divide between Male' and Atolls with respect to Personal Computer and Fixed Line penetration

\subsubsection{The Digital Divide across the Maldives}

We now investigate Digital Divide across the Maldives. We employ Lorenz curves and Gini coefficients to quantify the disparity across the twenty Atolls plus the capital based on their household ICT penetration, i.e. treating the country as 21 groups defined by numbers of households and household ICT penetrations.

The Lorenz curves for Internet connections, personal computers, and fixed and mobile phones are shown in Figure 5, with Gini coefficients corresponding to these curves summarised in Table 1. From Figure 5 and Table 1 it is evident that the 


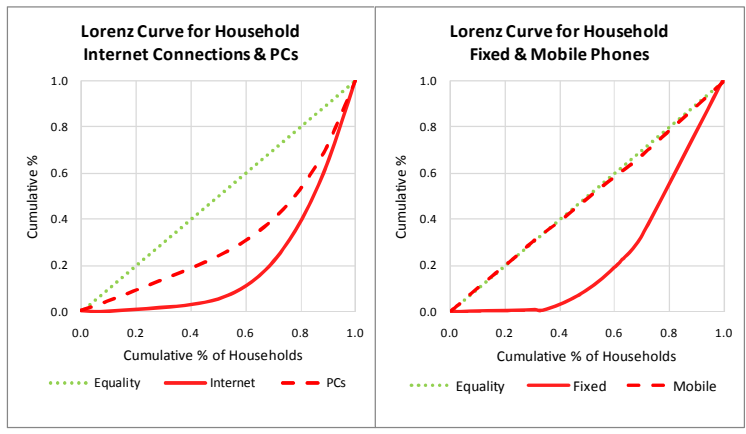

Fig. 5. Lorenz Curves for Household ICT Penetration in the Maldives, 2006

Table 1. Gini Coefficients for Household ICT Penetration in the Maldives, 2006

\begin{tabular}{lc}
\hline \multicolumn{1}{c}{ ICT } & GINI Coefficient \\
\hline Internet Connections & 0.57 \\
Fixed Line Phones & 0.48 \\
Personal Computers & 0.34 \\
Mobile Phones & 0.02 \\
\hline
\end{tabular}

penetration of the Internet is the most divisive factor across the country, followed by household fixed line telephones and personal computers. It is also clear that there is no Digital Divide with respect to mobile phones. From the Lorenz curves, $60 \%$ of the households with the least household ICT access have about $10 \%$ of the household Internet connections, $30 \%$ of the personal computers and $20 \%$ of the fixed phone lines. This demonstrates that large parts of the country have little access to ICT at home, while at the same time the country has equal access to mobile technology.

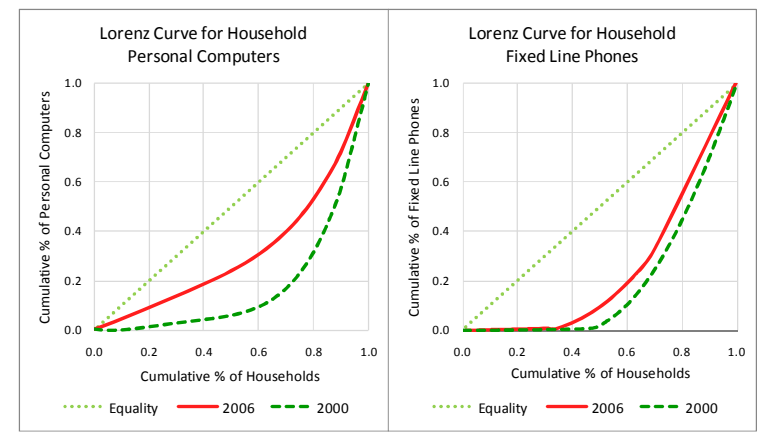

Fig. 6. Evolution of the Digital Divide across the Maldives with respect to PC and Fixed Line penetration 
Table 2. Gini Coefficients for Household ICT Penetration in the Maldives, 2000 and 2006

\begin{tabular}{ccc}
\hline ICT & $\mathbf{2 0 0 0}$ & $\mathbf{2 0 0 6}$ \\
\hline Personal Computers & 0.58 & 0.34 \\
Fixed Line Phones & 0.56 & 0.48 \\
\hline
\end{tabular}

We now examine the evolution of the divide within the Maldives. In particular, we construct the Lorenz curves and estimate the Gini coefficients for household personal computers and fixed line phones across the country, as shown in Figure 6 and Table 2.

From Figure 6 and Table 2 we can observe that the disparity in the distribution of household personal computers and fixed phone lines across the Maldives has decreased, pointing to a narrowing of the divide across the country. It is interesting to note that the disparity in household fixed phone lines has only decreased by a small factor, in comparison to the household personal computers' penetration. This is consistent with the rapid uptake of mobile technologies in the Maldives and across the world, and the corresponding slowing-down of the fixed phone line penetration in many parts of the world, as highlighted in the World Information Society Report 2007 [15].

\subsubsection{Atoll Clusters}

In Sections 4.2.1 and 4.2.2 we examined and quantified Digital Divide across the Maldives as well as between the capital Male' and the rest of the country. From this analysis, it is clear that there is a substantial divide between Male' and the Atolls, and substantial disparity in ICT penetration across the country as a whole. This suggests that the Male'-Atolls divide may not be the only substantial Digital Divide in the country, and that there are possible other divides within the group of 20 Atolls.

In this section, we examine Digital Divide using the clustering technique explained in Section 3.2. We employed self-organising, map-based clustering using the household penetration of personal computers and fixed phone lines for 2000 and 2006 as well as Internet connections and mobile phones for 2006 , to produce possible clusters of Atolls.

From this analysis, we identified six clusters of Atolls with varying ICT profiles, thus pointing to the possibility of further splits within 20 Atolls. The numbers of Atolls in each of these clusters are given in Table 3, while the 2006 ICT profiles of these clusters are shown in Figure 7. From Figure 7 we can observe the differences in the ICT profiles of these clusters and consequently, their different divide challenges. Clusters A and B have the most developed and similar profiles, but are distinguished by their relative Internet penetration rates. The least developed clusters, $\mathrm{E}$ and $\mathrm{F}$, while similar in many aspects, are distinguished by their fixed phone line penetration.

Table 3. Atolls Clusters

\begin{tabular}{lcccccc}
\hline Cluster & A & B & C & D & E & F \\
\hline No of Atolls & 1 & 1 & 2 & 5 & 3 & 7 \\
\hline
\end{tabular}




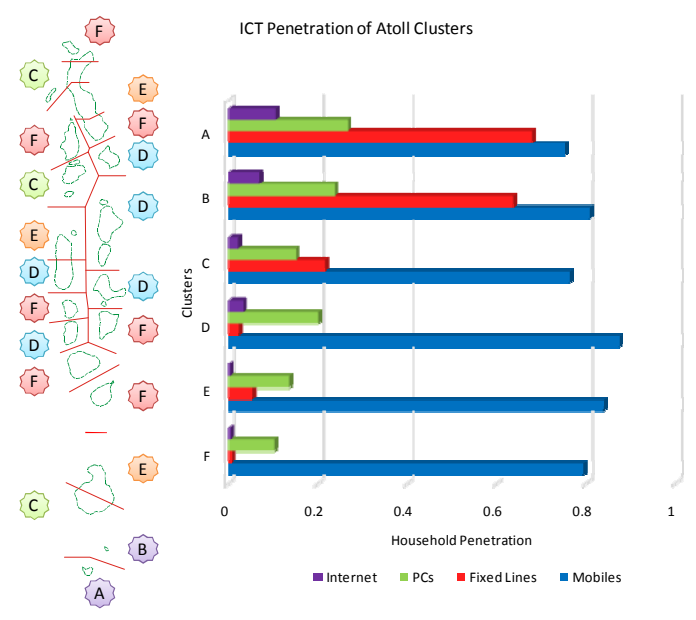

Fig. 7. Clusters and their ICT Profiles

Digital Divide between these clusters in terms of the penetration gap is shown in Figure 8; the cluster with the best penetration is taken as the reference for each ICT measure. The figure makes the divide between Atoll clusters evident. The divide is severe with respect to fixed phone lines and Internet connections while negligible with respect to mobile phones: this is consistent with overall Digital Divide characteristics which were presented in previous sections. This suggests that this clustering retains the main characteristic of the country's Digital Divide.

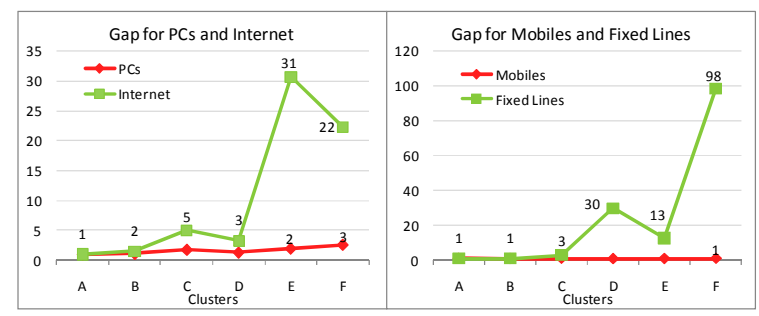

Fig. 8. Digital Divide between the Clusters

\subsubsection{Determinants of the Digital Divide}

Having explored and quantified Digital Divide across the Maldives, we now examine the possible impact of the country's geographic and demographic features on the divide, particularly on Internet and personal computer penetration. To this end, we investigate the presence of significant relationships between Internet and personal computer penetration, distance of the Atolls from Male', and the numbers of islands in each Atoll with a population below 500.

Table 4 presents the coefficients for the 20 Atolls. From this table, we observe that there is a significant positive correlation between the distance of Atolls from Male' 
and their Internet penetration, and a significant negative correlation between the number of small islands in an Atoll and the Internet penetration in the Atoll. While the negative correlation between the number of small islands in an Atoll and their Internet penetration is in line with popular understanding, the positive correlation between the distance of the Atolls from Male' and their Internet penetration is interesting. This could be explained by disproportionate development of the two southernmost Atolls, as identified in our clustering analysis in Section 4.2.3.

Table 4. Relationships between geographic and demographic dispersion and Digital Divide

\begin{tabular}{lccc}
\hline \multicolumn{1}{c}{ Feature } & Internet & PC & Mobile \\
\hline Distance from Atolls to Male & 0.5421 & 0.1868 & -0.6060 \\
$\begin{array}{l}\text { No. of islands with <500 population } \\
\text { in the Atoll }\end{array}$ & -0.5810 & -0.4873 & 0.02315 \\
\hline
\end{tabular}

Therefore, we examine the correlations between the 18 Atolls, excluding the two southernmost Atolls (clusters A and B). This is presented in Table 5. The table shows that all correlations are negative, in line with popular understanding. However, apart from the correlation between the distance of the Atolls from Male' and the mobile phone penetration, other correlations are not significant. While simple correlation does not establish causality between variables, the apparent lack of significant correlation between Internet and personal computer penetration, and geographic and demographic dispersion, requires further investigation.

Table 5. Relationships between geographic and demographic dispersion and Digital Divide (excluding Clusters A and B)

\begin{tabular}{lccc}
\hline \multicolumn{1}{c}{ Feature } & Internet & PC & Mobile \\
\hline Distance from Atolls to Male' & -0.1665 & -0.3775 & -0.6360 \\
$\begin{array}{l}\text { No. of islands with <500 population } \\
\text { in the Atoll }\end{array}$ & -0.3160 & -0.2590 & -0.1234 \\
\hline
\end{tabular}

\subsection{Findings}

We illustrated in previous sections the nature of Digital Divide across Maldivian Atolls. We now summarise these findings with respect to our research questions:

\section{How are the Atolls of the Maldives divided with respect to ICT access?}

The nation shows wide dispersion in the penetration of household Internet and personal computers. A significant divide exists between the nation's capital Male' and the rest of the Atolls. In addition, significant differences exist among the Atolls as seen from the clustering analysis; six clusters of Atolls with distinctive Digital Divide challenges were identified in our analysis. On the other hand, we found no significant divide with respect to the penetration of mobile telephony across the nation. 


\section{How significant is the geographic and demographic distribution of the Atolls to Digital Divide?}

While the challenges of geographic and demographic dispersion to national development are fairly well accepted, our analysis found that the relationship between these features and Digital Divide may be less significant. This warrants further investigation of the impact of these factors on Digital Divide, not just from the physical access or possession point of view, but also from the point of view of the usage of and benefit from ICT.

\section{Conclusions}

The primary aim of the work reported in this paper is to understand the nature of Digital Divide in the small island developing state of the Maldives in order to better inform ICT policy and strategy development at the national level.

In line with this aim, we illustrated and quantified the divide across the country and between the capital and the rest of the country (Atolls). We also applied clustering analysis to obtain a better insight into possible divides between the Atolls. Finally, we investigated the impact on Digital Divide of two of the most significant challenges to national development - the geographic and demographic nature of the island nation.

Our findings indicate the presence of a significant Digital Divide across the country. They also suggest that geographic and demographic features - the distance of the Atolls from Male' and the numbers of small island communities within Atolls, may not be significant with respect to Digital Divide. However, a more thorough analysis is warranted, possibly along the identified Atoll clusters.

Based on the findings, we propose that in addition to more detailed studies of the main determinants of Digital Divide, efficient and purposeful strategies to overcome Digital Divide could be formulated based on Atoll clusters with similar Digital Divide profiles. These strategies could complement national and regional strategies, and rely on knowledge-sharing and collaborative action through communities of interests or other collective measures. In addition we propose that, given the varied nature of Digital Divide across the country, special consideration be given to infoethics to ensure that ICT development impacts positively the development of human rights.

\section{References}

1. Campbell, D.: Can the Digital Divide be Contained? International Labour Review 140(2), 119-141 (2001)

2. Chakraborty, J., Bosman, M.M.: Measuring the Digital Divide in the United States: Race, Income, and Personal Computer Ownership. The Professional Geographer 57(3), 395-410 (2005)

3. Chinn, M.D., Fairlie, R.: The Determinants of the Global Digital Divide: Across-Count Analysis of Computer and Internet Penetration. Yale University, Working Papers 881 (2004)

4. Compaine, B.M.: Re-Examining the Digital Divide. Center for eBusiness @ MIT. MIT Sloan School of Management (2001),

http: / / ebusiness.mit.edu/research/papers /

130\%20Compaine, \%20Digital\%20Divide.pdf 
5. Dewan, S., Ganley, D., Kraemer, K.L.: Across the Digital Divide: A Cross-Country MultiTechnology Analysis of the Determinants of IT Penetration. Journal of the Association for Information Systems 6(12), 409-443 (2005)

6. DNP. Population and Housing Census of Maldives 2000. Department of National Planning, Government of Maldives (2000)

7. DNP. Population and Housing Census of Maldives 2006. Department of National Planning, Government of Maldives (2006).

8. DNP. Statistical Year Book 2007. Department of National Planning, Government of Maldives (2007)

9. Guillén, M.F., Suárez, S.L.: Explaining the Global Digital Divide: Economic, Political, and Sociological Drivers of Cross-National Internet Use. Social Forces 8(2), 681-708 (2005)

10. Hargittai, E.: Weaving the Western Web: Explaining Differences in Internet Connectivity Among OECD Countries. Telecommunications Policy 23(10/11), 701-718 (1999)

11. Hawkins, S.: Beyond the Digital Divide: Issues of Access and Economics. The Canadian Journal of Information and Library Sciences 29(2), 171-189 (2005)

12. IGADD. DigitalDivide.org. Invester Group against Digital Divide, IGADD (2009), http: / / www.digitaldivide.org/

13. ITU. Bridging the Digital Divide. International Telecommunication Union, Geneva (2004)

14. ITU. ICT EYE. International Telecommunication Union (2009)

15. ITU. World Information Society Report 2007. International Telecommunication Union, Geneva (2007)

16. Jin, J., Cheong, A.W.H.: Measuring Digital Divide: The Exploration in Macao. Observatorio $(\mathrm{OBS} *)$ 2(3), 259-272 (2008)

17. Kohonen, T.: Self-Organizing Maps. Springer, Heidelberg (2001)

18. Maitland, C.F., Bauer, J.M.: National Level Culture and Global Diffusion: The Case of the Internet. In: Ess, C. (ed.) Culture, Technology, Communication: Towards an Intercultural Global Village. State University of New York Press, Albany (2001)

19. Norris, P.: Digital Divide: Civic Engagement. In: Information Poverty, and the Internet Worldwide. Cambridge University Press, Cambridge (2001)

20. Ofcom. Citizens' Digital Participation. OfCom - Office of Communications, United Kingdom (2009)

21. Robinson, K.K., Crenshaw, E.M.: Cyber-Space and Post-Industrial Transformations: A Cross-National Analysis of Internet Development (1999)

22. Rundle, M., Comley, C.: Ethical Implications of Emerging Technologies: A Survey. UNDESCO, Paris (2007)

23. UNCTAD. The Digital Divide: ICT Development Indices 2004. United Nations Conference on Trade and Development, United Nations, New York and Geneva (2005)

24. UNDESA. UN Global E-government Survey 2003. United Nations Department of Economic and Social Affairs, United Nations, New York (2003)

25. UNESCO. Internet Governance Forum (IGF) - The First Two Years. A UNESCO Publications for the World Summit of the Information Society - Special issue co-produced with the ITU and UNDESA (2008)

26. Van Dijk, J., Hacker, K.: The Digital Divide as a Complex and Dynamic Phenomenon. The Information Society 19, 315-326 (2003) 